\title{
SOD1-G93A Mice Exhibit Muscle-Fiber-Type-Specific Decreases in Glucose Uptake in the Absence of Whole-Body Changes in Metabolism
}

\author{
Susan E. Smittkamp ${ }^{a} \quad$ Jill K. Morris ${ }^{b}$ Gregory L. Bomhoff ${ }^{a}$ Mark E. Chertoffc, d \\ Paige C. Geiger ${ }^{a, d}$ John A. Stanford ${ }^{a, d}$ \\ Departments of a Molecular and Integrative Physiology, ${ }^{\mathrm{b}}$ Neurology, and ${ }^{\mathrm{c} H e a r i n g}$ and Speech, and the \\ dKansas Intellectual and Developmental Disabilities Research Center, University of Kansas Medical Center, \\ Kansas City, Kans., USA
}

\section{Key Words}

Amyotrophic lateral sclerosis · Familial amyotrophic lateral sclerosis · Insulin · Metabolism · Skeletal muscles

\begin{abstract}
Background: Skeletal muscles play an important role in systemic glucose homeostasis and are purported to be the origin of the altered metabolic state observed in amyotrophic lateral sclerosis (ALS). Objective: The purpose of this study was to evaluate whole-body and muscle-specific glucose metabolism in the SOD1-G93A mouse model of ALS. Methods: We assessed glucose tolerance in early-, middle-, and late-stage SOD1-G93A and control mice using an intraperitoneal glucose tolerance test. We then measured the respiratory exchange ratio $\left(\mathrm{CO}_{2}\right.$ production $/ \mathrm{O}_{2}$ consumption) as a function of fasting and feeding using indirect calorimetry in a subset of male mice at these time points. Finally, muscles from all mice were harvested to evaluate basal and insulinstimulated glucose transport in fast- and slow-twitch muscles. Results: No changes in systemic glucose clearance were observed in SOD1-G93A mice at any stage, nor were there changes in fasting insulin levels. Indirect calorimetry revealed an increase in the respiratory exchange ratio during the fed state at middle, but not at early or late stages of disease. Middle-stage SOD1-G93A mice exhibited decreased
\end{abstract}

insulin-stimulated glucose uptake in fast-twitch, but not slow-twitch, skeletal muscle. Late-stage SOD1-G93A mice exhibited decreased insulin-stimulated glucose uptake in both fast- and slow-twitch muscle, as well as increased basal (non-insulin-stimulated) glucose uptake. Conclusions: These results suggest that alterations in muscle metabolism occur in a fiber-type-specific manner in ALS, but do not necessarily lead to whole-body metabolic changes in SOD1G93A mice.

C) 2013 S. Karger AG, Basel

\section{Introduction}

Amyotrophic lateral sclerosis (ALS) is a progressive degenerative disease characterized by muscle weakness, paralysis, and eventual death. ALS affects upper and lower motor neurons, with marked weakness/atrophy, fasciculations, and reflex abnormalities in the innervated muscles occurring secondary to motor neuron degeneration [1]. Recent evidence calls for a wider perspective on this multisystem disease, however. Some of the earliest signs of disease are seen in skeletal muscles long before the occurrence of motor neuron loss, including chronic weakness, neuromuscular junction pathology, and changes in gene regulation [2-8]. Although a causative role in

\section{KARGER}

E-Mail karger@karger.com

www.karger.com/ndd (c) 2013 S. Karger AG, Basel

$1660-2854 / 14 / 0131-0029 \$ 39.50 / 0$
John A. Stanford, $\mathrm{PhD}$

Department of Molecular and Integrative Physiology University of Kansas Medical Center, Mail Stop 3051 3901 Rainbow Blvd., Kansas City, KS 66160 (USA)

E-Mail jstanford@kumc.edu 
early disease processes is controversial $[9,10]$, skeletal muscles appear to be an early target of the disease. Thus, closer investigation of muscle function as it relates to ALS symptom onset and progression is warranted.

One potential target for investigation of skeletal muscles in motor neuron disease is peripheral glucose regulation. Skeletal muscles are the peripheral tissue responsible for the majority of glucose disposal in the body and thus play an important role in systemic glucose homeostasis [11]. Defects in skeletal muscle glucose uptake are associated with insulin resistance. It follows that a disease that affects skeletal muscles such as ALS does will also affect glucose regulation and metabolism. While some studies document normal glucose tolerance and insulin secretion in ALS patients [12-17], others report impairment [18-25]. Recent studies have also reported hypermetabolism in patients with ALS $[26,27]$. Due to these discrepancies, it is important to determine the metabolic status of skeletal muscles in ALS, at different stages of disease, in order to determine whether drugs that increase muscle metabolism are appropriate.

The most common animal models of ALS are mice that express mutations in the gene coding for superoxide dismutase (SOD1). These models emerged after discovery of SOD1 mutations that accounted for a majority of the known familial forms of ALS [28, 29]. Although the mechanisms are unclear, these mutations are believed to result in a toxic 'gain of function' that leads to the ALS phenotype. Using SOD1 transgenic mice, Dupuis et al. [30] reported altered metabolic activity in these models of ALS. Most of their findings involved SOD1-G86R mice. The purpose of our study was to evaluate wholebody and muscle-fiber-type-specific glucose metabolism in the more commonly studied SOD1-G93A mutant mouse [28]. We assessed whole-body metabolism and glucose tolerance in early (weanling)-, middle (presymptomatic)-, and late-stage (symptomatic) SOD1-G93A mice and age-matched wild-type littermates using a variety of measures. Although we did not confirm symptom onset in these animals, we selected ages based on numerous prior studies in this consistent and well-characterized model, including our own previous study [31]. Because denervation in ALS occurs in a muscle-fiber-type-specific pattern (beginning with fast-twitch type II fibers and progressing to slow-twitch type I fibers) $[5,7,32]$ we compared slow-twitch (soleus) and fast-twitch (extensor digitorum longus, EDL) fiber types. We are aware of no studies that have examined muscle-fiber-type-specific glucose uptake in the context of whole-body metabolism in ALS.

\section{Materials and Methods}

A breeding colony was established with 2 male B6SJL-Tg (SOD1-G93A)1Gur/J (SOD1-G93A) and 8 female noncarrier (control) mice obtained from the Jackson Laboratory. The offspring of these breeders served as subjects in this experiment. Tail clips were sent to Transnetyx, Inc., for genotyping. Mice were housed in groups in an animal care facility approved by the Association for Assessment and Accreditation of Laboratory Animal Care International with free access to food and water, and were maintained on a 12-hour-light/12-hour-dark cycle. Mice were evaluated at 3 different stages: early-stage mice were aged 30-40 days; middle-stage mice were aged 65-75 days, and late-stage mice were aged 105-115 days. All procedures were approved by the University of Kansas Medical Center Institutional Animal Care and Use Committee and were carried out in accordance with the NIH Guide for the Care and Use of Laboratory Animals.

Body weight was recorded and systemic glucose tolerance was determined using an intraperitoneal glucose tolerance test in female and male early-, middle-, and late-stage control and SOD1G93A mice ( $n=12$ control and $n=12$ SOD1-G93A mice at each stage). Mice were fasted overnight ( $\sim 12 \mathrm{~h})$ prior to testing. Body weight was recorded and basal glucose values were obtained from tail blood using a glucometer (Accucheck Active). The glucose load ( $60 \%$ glucose in $0.9 \%$ saline; 2 g glucose $/ \mathrm{kg}$ i.p.) was administered and glucose values were obtained $15,30,60$, 90, and $120 \mathrm{~min}$ after injection.

Fasting insulin levels were evaluated in a subset of female and male early-, middle-, and late-stage control and SOD1-G93A mice using a mouse insulin ELISA kit (Alpco Diagnostics; $n=6$ control and $n=6$ SOD1-G93A mice at each stage). Plasma was prepared from blood obtained during cardiac puncture and insulin levels were determined spectrophotometrically, according to the manufacturer's directions. The homeostasis model assessment of insulin resistance (HOMA-IR [33]) was calculated in these mice using the following equation: [fasting blood glucose $(\mathrm{mg} / \mathrm{dl}) \times$ fasting plasma insulin (ng/ml)]/405.

Oxygen consumption, carbon dioxide production and body temperature were evaluated in a subset of age-matched male early-, middle-, and late-stage control and SOD1-G93A mice using an open-circuit indirect calorimetric system (Columbus Instruments; $\mathrm{n}=4$ control and $\mathrm{n}=4$ SOD1-G93A mice at each stage). Mice were placed in individual metabolic chambers for 24-hour test sessions. The light/dark cycle was maintained during testing and test sessions were initiated at the beginning of the dark portion of the cycle. Mice were fasted during the first $12 \mathrm{~h}$ of testing. Food pellets were inserted for the remaining $12 \mathrm{~h}$. Baseline respiratory exchange ratio $\left(\mathrm{VCO}_{2} / \mathrm{VO}_{2}\right), \mathrm{O}_{2}$ consumption, $\mathrm{CO}_{2}$ production, and body temperature were analyzed during the final seven 4-min data points prior to feeding. For statistical analysis of the shift from basal to carbohydrate metabolism following feeding, the time series was truncated to include data from $28 \mathrm{~min}$ ( 7 data points, $4 \mathrm{~min} /$ point) before the onset of the rise in the function to the end of the data series. The mean of the seven data points was computed for each animal and subtracted from each individual's data. All the results from animals in each group were combined and fit to the following function,

$$
y=a\left(1-e^{-\frac{\left(x-x_{0}\right)}{b}}\right) .
$$

30

Neurodegener Dis 2014;13:29-37

DOI: $10.1159 / 000351606$
Smittkamp/Morris/Bomhoff/Chertoff/ Geiger/Stanford 


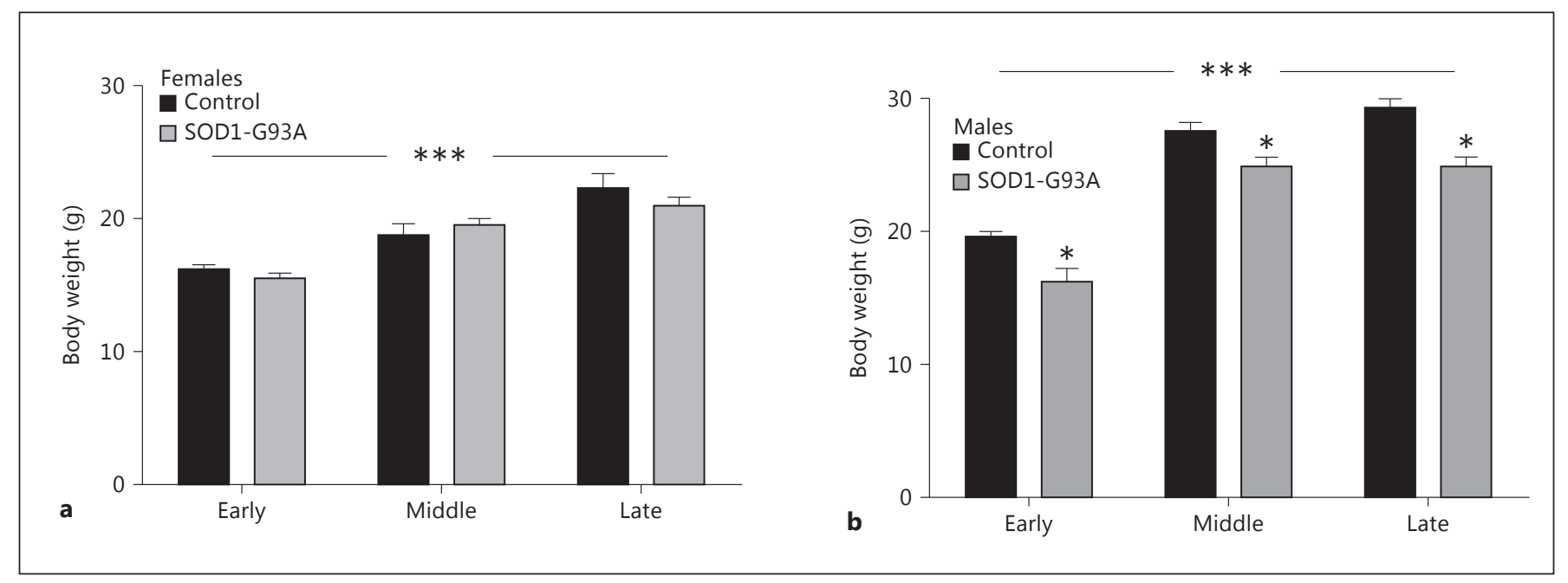

Fig. 1. Mean body weight $( \pm$ SEM) for control and SOD1-G93A mice at early, middle and late stages. a Female mice exhibited age-related increases in body weight but did not differ according to genotype. $\mathbf{b}$ Male mice exhibited age-related increases in body weight, but SOD1-G93A mice weighed less than control mice at each stage. ${ }^{*} \mathrm{p}<0.05,{ }^{* * *} \mathrm{p}<0.0001$.

The parameter $a$ is a value where the function saturates, $b$ is the time constant (i.e. the time it takes for the function to rise to $63 \%$ of its maximum value), and $x_{0}$ is the shift of the function along the abscissa. The function was fit using the Marquardt-Levenberg algorithm supplied in Sigmaplot 11.0. Student's t test was used for between-group comparisons of the means and standard errors of the means for $a$ and $b$. In addition to the above measures, measurements of food pellet weight and water volume were performed before and after the sessions to monitor food and water consumption during the test sessions. Body weights were also recorded before and after the sessions.

Skeletal muscle glucose transport was evaluated in the EDL (fast-twitch) and soleus (slow-twitch) muscles from the mice used for the insulin ELISA and HOMA-IR. Mice were fasted overnight $(\sim 12 \mathrm{~h})$ prior to tissue harvest. As previously done in our laboratory [34], mice were deeply anesthetized with sodium pentobarbital (Nembutal, $50 \mathrm{mg} / \mathrm{kg}$ ) and muscles were dissected and allowed to recover in Krebs-Henseleit buffer for $1 \mathrm{~h}$. Muscles were then incubated in the presence or absence of insulin $(1 \mathrm{mU} / \mathrm{ml})$ in flasks containing oxygenated Krebs-Henseleit buffer and $2\left[1,2-{ }^{3} \mathrm{H}\right]$-deoxyglucose $(1.5 \mu \mathrm{Ci} / \mathrm{ml})$ and $\left[{ }^{14} \mathrm{C}\right]$ mannitol $(0.2 \mu \mathrm{Ci} / \mathrm{ml})$. Intracellular 2-deoxyglucose ( ${ }^{3} \mathrm{H}$ DPM $)$ and extracellular space $\left({ }^{14} \mathrm{C} \mathrm{DPM}\right)$ were quantified in a scintillation counter.

\section{Results}

\section{Body Weight}

Body weights were analyzed separately for female and male mice. In the females, body weight increased as a function of age group $\left(\mathrm{F}_{2,32}=32.5249, \mathrm{p}<0.0001\right.$; fig. 1a). There were no differences in body weight between SOD1-
G93A and controls at any stage, nor did the increases in body weight differ between the two groups. Like the females, there was a significant increase in body weight with age in the males $\left(\mathrm{F}_{2,38}=106.078, \mathrm{p}<0.0001\right)$. Unlike the females, SOD1-G93A male mice weighed less than their wild-type littermates at each stage, leading to a main effect for genotype $\left(F_{1,38}=35.6902, p<0.0001\right.$; fig. $\left.1 b\right)$. Body weight increases were similar between the SOD1G93A and wild-type mice at these time points.

\section{Indirect Calorimetric Metabolic Activity}

SOD1-G93A mice and controls did not differ with regard to the respiratory exchange ratio during the prefed state at any disease stage. Upon feeding, middle-stage SOD1-G93A mice achieved a significantly higher ratio of $\mathrm{CO}_{2}$ produced $/ \mathrm{O}_{2}$ consumed $\left(\mathrm{t}_{282}=13.47, \mathrm{p}<0.0001\right)$, indicating greater carbohydrate metabolism in this group (fig. 2). In addition to their greater maximal ratio, the rate of the increase from 0.7 to 1.0 (indicating a feeding-related shift from fat to carbohydrate metabolism) was significantly greater in SOD1-G93A mice during the middle stage $\left(t_{282}=3.08, p<0.05\right)$. Metabolic test sessions led to essentially no changes in body weight $(-0.67 \pm 0.2 \mathrm{~g} / \mathrm{ses}-$ sion). No significant differences between SOD1-G93A mice and controls were revealed for $\mathrm{O}_{2}$ consumption, $\mathrm{CO}_{2}$ production, body temperature, food or water consumption, or differences in body weight, during either the fasted or fed state at any stage (data not shown). 


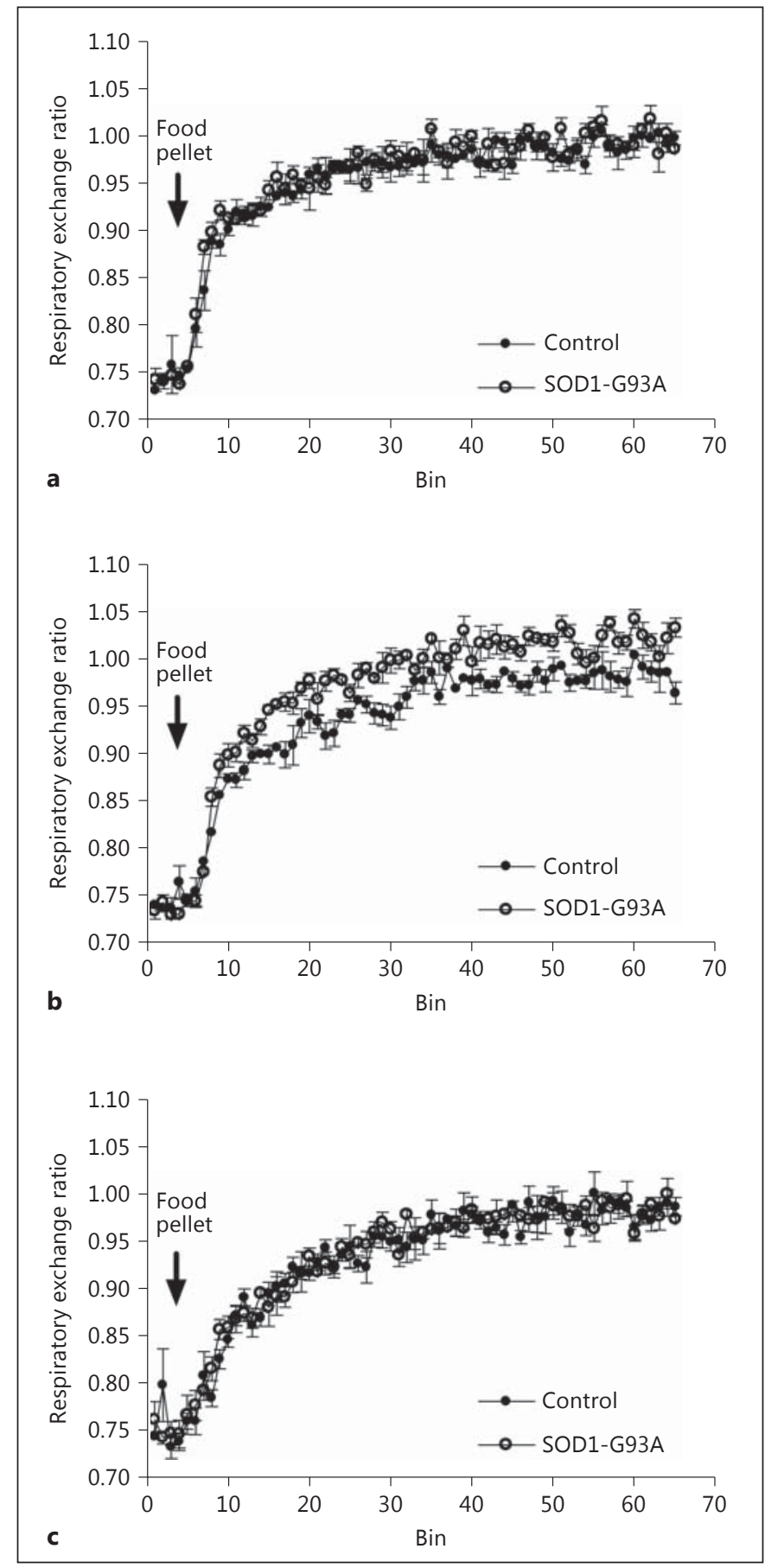

Fig. 2. Respiratory exchange measured with indirect calorimetry in male control and SOD1-G93A mice at early (a), middle (b) and late stages $(\mathbf{c})$. Each time bin $=4 \mathrm{~min}$. Each graph shows the final seven time bins prior to feeding (respiratory exchange ratio values before feeding did not differ between the SOD1-G93A and control mice at any stage). At middle stage, the SOD1-G93A mice exhibited a faster and greater shift in the respiratory exchange ratio after feeding indicating greater carbohydrate metabolism at this disease stage. Respiratory exchange did not differ significantly between the SOD1G93A and control mice during either early or late disease stages.
Fasting Glucose, Glucose Clearance, Fasting Insulin and HOMA-IR

No significant differences between SOD1-G93A and wild-type male and female mice were revealed for fasting blood glucose in early, middle, or late stages (fig. 3a-c: time point 0 ). Likewise, glucose clearance did not differ between SOD1-G93A and controls at any disease stage (fig. 3a-c: time points 15-120 min). No significant differences in fasting insulin (fig. 3d) or in HOMA-IR (data not shown) were revealed at early, middle or late stages, or between male and female mice, suggesting that fasting serum insulin levels and insulin function in early-, middle-, and late-stage SOD1-G93A mice are similar to that of control mice.

\section{Muscle Glucose Uptake}

In the presence of insulin, 2-deoxyglucose uptake was increased in the EDL at the early $\left(\mathrm{F}_{1,20}=14.11, \mathrm{p}=0.001\right)$, middle $\left(\mathrm{F}_{1,15}=13.82, \mathrm{p}<0.01\right)$, and late stages $\left(\mathrm{F}_{1,16}=\right.$ $4.46, \mathrm{p}=0.05$; fig. 4$)$ of male and female mice. Post hoc comparisons ( $t$ tests) revealed that a significant increase in 2-deoxyglucose uptake occurred in both control and SOD1-G93A EDL muscles at the early stage, but only in control EDL muscles at the middle and late stages (all $\mathrm{p}<$ $0.05)$. In addition, basal 2-deoxyglucose uptake was significantly increased in late-stage SOD1-G93A EDL muscles (fig. 4e). In the soleus, 2-deoxyglucose uptake was increased in the presence of insulin at the early $\left(\mathrm{F}_{1,16}=\right.$ 21.32, $\mathrm{p}<0.001)$, middle $\left(\mathrm{F}_{1,15}=19.55, \mathrm{p}<0.001\right)$, and late stages $\left(\mathrm{F}_{1,17}=9.25, \mathrm{p}<0.01\right)$. Post hoc comparisons ( $t$ tests) revealed that the significant increase in insulinstimulated 2-deoxyglucose uptake occurred in both control and SOD1-G93A soleus muscles at the early and middle stages (all $\mathrm{p}<0.05$ ), but only in control soleus muscles at the late stage.

\section{Discussion}

Overall, our results indicate that despite decreased insulin-stimulated glucose uptake in skeletal muscles in middle and late stages of disease, SOD1-G93A mice do not exhibit alterations in systemic glucose metabolism. Our results also show that changes in glucose uptake occur in a fiber-type-specific manner, with changes occurring first in fast-twitch skeletal muscles and then in slowtwitch muscles. SOD1-G93A mice also exhibited increased carbohydrate metabolism following feeding during the middle stage measured by indirect calorimetry. These findings indicate that SOD1-G93A mice do not 


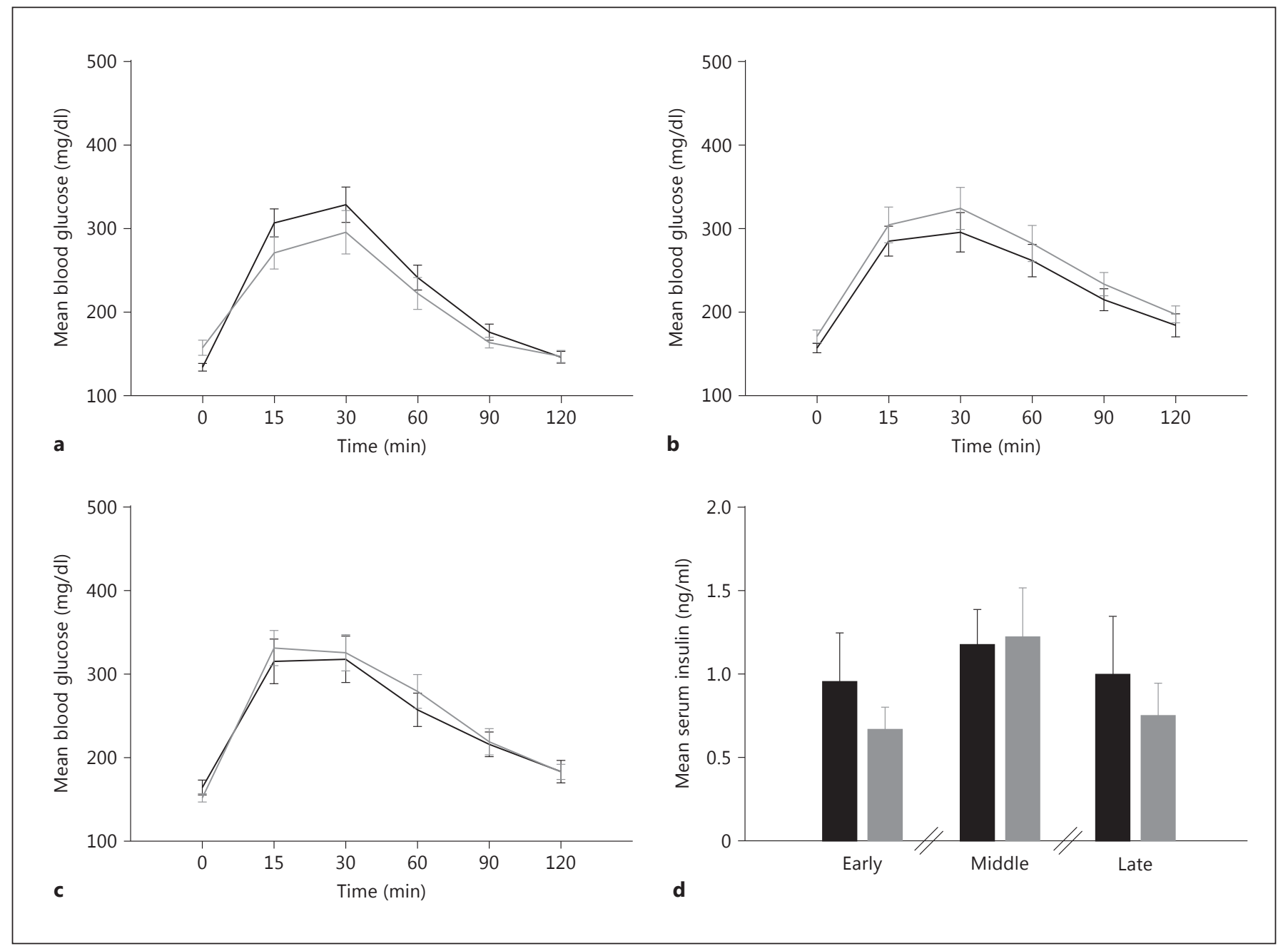

Fig. 3. a-c Mean blood glucose ( \pm SEM) over time for control (black lines) and SOD1-G93A mice (grey lines) at the early, middle, and late stages. Male and female mice were combined within groups. Systemic glucose clearance in early-, middle-, and latestage SOD1-G93A mice did not differ significantly from that of control mice. d Mean serum insulin ( \pm SEM) for control (black bars) and SOD1-G93A mice (grey bars) at the early, middle, and late stages. At each stage, 2-sample t tests revealed no significant differences in mean serum insulin between control and SOD1G93A mice. Breaks indicate that across-stage comparisons were not performed. exhibit systemic metabolic deficits, but that fiber-typespecific changes in neuromuscular function lead to altered glucose uptake in skeletal muscles.

\section{Body Weight}

Our findings regarding the effects of the SOD1-G93A mutation on body weight in mice are consistent with previous preclinical studies, which report weight changes at widely variable points during the course of the disease $[8$, 31, 35-37]. Decreased body weight in this model has been attributed to several factors, including muscle wasting
[38], increased metabolism [30], and decreased food intake due to orolingual motor deficits $[31,39,40]$. We and others have reported evidence of orolingual motor deficits in this model, but our findings do not support decreased food intake as an explanation for weight loss in these animals. Our results also do not support increased metabolism as a contributing factor. Although we did not measure muscle mass, our findings regarding decreased glucose uptake in both muscle types at end stage are consistent with muscle wasting, however. 


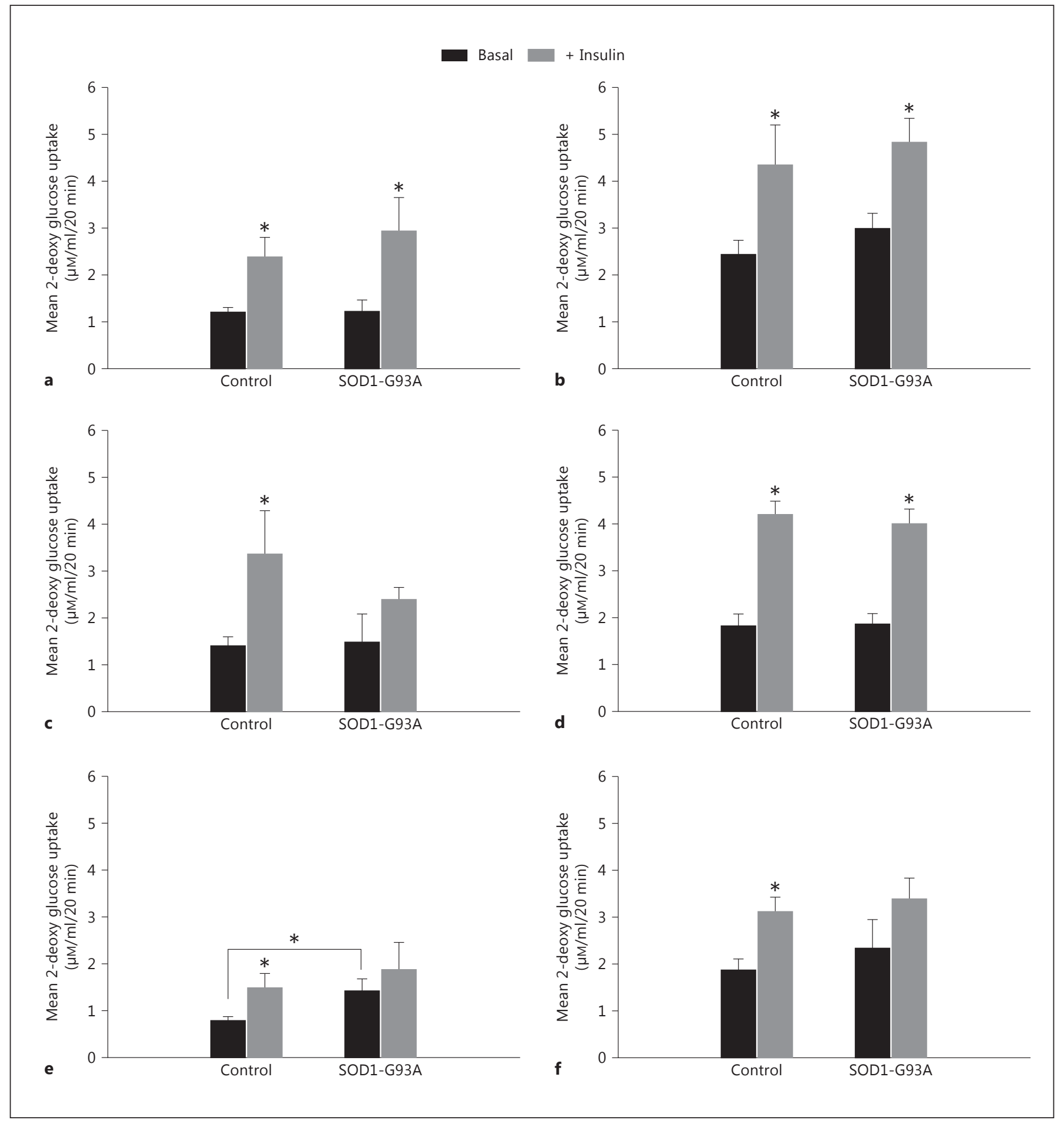

Fig. 4. Mean glucose transport ( \pm SEM) for control and SOD1G93A EDL (a, c, e) and soleus (b, d, f) muscles at the early (a, b), middle (c, d), and late stages $(\mathbf{e}, \mathbf{f})$. The addition of insulin increased glucose transport in EDL muscles in both groups during the early stage, but only in control animals at the middle and late stages. The addition of insulin increased glucose transport in soleus muscles in both groups during the early and middle stages, but only in control animals at the late stages. ${ }^{*} \mathrm{p}<0.05$. 


\section{Systemic Glucose Metabolism}

Muscle wasting is associated with the development of systemic insulin resistance [18]. However, studies of glucose tolerance in ALS patients report conflicting results [12-25]. The choice of control groups may have accounted for some of the inconsistencies in these studies. One well-controlled study compared a healthy with a neuromuscular-disease control group, and reported significant insulin resistance in ALS patients that could not be explained by a decrease in functioning muscle mass [23]. A more recent study confirmed that a subset of ALS patients exhibited impaired systemic glucose clearance that was unrelated to muscle atrophy [38].

Altered systemic metabolism and glucose homeostasis are recapitulated in SOD1-G86R mice [30]. Interestingly, however, these animals exhibit increased whole-body metabolism and augmented systemic glucose clearance rather than impairment. Despite similar neuromuscular phenotypes in SOD1-G86R and SOD1-G93A mice [39], we found no significant differences in systemic glucose clearance in early-, middle-, or late-stage SOD1-G93A mice when they were compared to age-matched controls. In addition (and also unlike the SOD1-G86R mice [30]), we measured no differences in fasting glucose or fasting insulin levels, or in the HOMA-IR assessment of insulin resistance, at any stage examined. Although our finding of increased carbohydrate metabolism in 75-day-old SOD1-G93A mice measured using indirect calorimetry was consistent with the findings of Dupuis et al. [30] in similarly aged SOD1-G93A mice, these authors reported increased metabolism at subsequent ages in SOD1-G86R mice. It is unclear what accounts for the metabolic differences between the G93A and G86R mutants because direct comparisons between them are few. Disease onset and duration are similar for these two models, but other factors have been reported to differ $[30,35]$. While these differences merit further study, our results indicate that, unlike SOD1-G86R mice, systemic glucose metabolism in SOD1-G93A mice is maintained at levels similar to controls throughout the course of disease.

\section{Muscle Denervation, Oxidative Stress, and Glucose Uptake}

Muscle denervation drastically increases the production of reactive oxygen species (ROS) [41]. Through the activation of serine/threonine kinases, oxidative stress negatively regulates the insulin signaling cascade [42]. In addition, oxidative stress alters the transcription of the glucose transporters responsible for basal and insulinstimulated glucose uptake (GLUT1 and GLUT4, respec- tively), resulting in increased basal glucose uptake, decreased insulin-stimulated glucose uptake, and the exacerbation of oxidative stress in the cell [43]. In accordance with this, experimental muscle denervation decreases GLUT4 mRNA and impairs GLUT4 translocation, thereby reducing insulin signaling and altering glucose uptake $[44,45]$.

ALS is characterized by oxidative stress, and the accumulation of ROS is believed to play a central role in disease pathogenesis [29]. Markers of oxidative stress and the activity of antioxidant enzymes are increased in SOD1-G93A muscles [41, 46, 47]. Importantly, a recent study shows a strong ROS-triggered upregulation of Rad (Ras-related associated with diabetes) protein in skeletal muscle from sporadic ALS patients as well as asymptomatic SOD1-G93A and SOD1-G86R mice [48]. This protein may negatively regulate glucose uptake in muscle and fat cells [49]. Muscle denervation in ALS occurs in a functional-fiber-type-specific manner [ $5,7,32]$. Synapses on type IIb fibers (fast twitch) undergo denervation first, followed by those on type IIa fibers (fast twitch). Synapses on type I fibers (slow twitch) are resistant until end stage. Evidence of oxidative stress in SOD1-mutant muscle is apparent before signs of denervation [48].

Accordingly, we found that SOD1-G93A mice exhibit alterations in skeletal muscle glucose uptake. By middle stage, these animals exhibited decreased insulin-stimulated glucose uptake in fast-twitch muscle. By late stage, insulin-stimulated glucose uptake was decreased in both fast- and slow-twitch muscles. This mimics the pattern of fiber-type-specific denervation described above $[5,7,32]$. In addition, an increase in basal, non-insulin-stimulated glucose uptake was apparent in late-stage fast-twitch muscles. Overall, our results suggest that while systemic glucose regulation is maintained in SOD1-G93A mice, disturbances occur in skeletal muscle glucose metabolism. Further study is required to determine the importance of these fiber types and their differential vulnerabilities in ALS-related metabolic disease.

\section{Conclusion}

Varying effects of different SOD1 mutations are documented in the literature $[50,51]$. Some of these differences extend to humans with familial, SOD1-related disease, underscoring the importance of the role of mutation type in disease pathogenesis $[41,52]$. ALS-related metabolic disturbances are still not fully understood, and evidence exists for differential effects of SOD1 mutations in 
altered glucose metabolism in ALS. Our studies of systemic and peripheral glucose metabolism in SOD1-G93A mice found that these animals developed fast-twitch muscle insulin resistance by 75 days of age. By end stage, both fast- and slow-twitch muscles were affected. In contrast, 60- to 80-day-old SOD1-G86R mice exhibit augmented systemic glucose metabolism, increased glucose uptake in skeletal muscle and white adipose tissue, and a hypermetabolic state [30]. Due to the equivocal state of the clinical literature regarding metabolism and ALS, any judgment regarding which rodent model best replicates metabolic function in the human disease is premature. These discrepancies highlight the need for further investigation into relationships between motor neuron disease, and whole-body and muscle metabolism.

\section{Acknowledgments}

This work was supported by NIH grants AG023549 and AG026491 to J.A.S., and by the Kansas Intellectual and Developmental Disabilities Research Center (HD02528).

\section{References}

1 Rowland LP, Shneider NA: Amyotrophic lateral sclerosis. N Engl J Med 2001;344:16881701.

-2 Azzouz M, Leclerc N, Gurney M, Warter JM, Poindron P, Borg J: Progressive motor neuron impairment in an animal model of familial amyotrophic lateral sclerosis. Muscle Nerve 1997;20:45-51.

-3 Canton T, Bohme GA, Boireau A, Bordier F, Mignani S, Jimonet P, Jahn G, Alavijeh M, Stygall J, Roberts S, Brealey C, Vuilhorgne M, Debono M-W, Le Guern S, Laville M, Briet D, Roux M, Stutzmann J-M, Pratt J: RPR 119990 a novel alpha-amino-3-hydroxy-5-methyl4-isoxazoleproprionic acid antagonist: synthesis, pharmacological properties, and activity in an animal model of amyotrophic lateral sclerosis. J Pharmacol Exp Ther 2001;299: 314-322.

4 Canton T, Pratt J, Stutzmann J-M, Imperato A, Boireau A: Glutamate uptake is decreased tardively in the spinal cord of FALS mice. Neuroreport 1998;9:775-778.

5 Frey D, Schneider C, Xu L, Borg J, Spooren W, Caroni P: Early and selective loss of neuromuscular synapse subtypes with low sprouting competence in motoneuron diseases. J Neurosci 2000;20:2534-2542.

6 Gonzalez de Aguilar J-L, Niederhauser-Wiederkehr C, Halter B, De Tapia M, Di Scala F, Demougin P, Dupuis L, Primig M, Meininger V, Loeffler J-P: Gene profiling of skeletal muscle in an amyotrophic lateral sclerosis mouse model. Physiol Genomics 2008;32:207-218.

$>7$ Hegedus J, Putman CT, Gordon T: Time course of preferential motor unit loss in the SOD1 G93A mouse model of amyotrophic lateral sclerosis. Neurobiol Dis 2007;28:154164.

8 Weydt P, Hong SY, Kliot M, Moller T: Assessing disease onset and progression in the SOD1 mouse model of ALS. Neuroreport 2003;14:1051-1054.

-9 Dobrowolny G, Aucello M, Rizzuto E, Beccafico S, Mammucari C, Boncompagni S, Belia S, Wannenes F, Nicoletti C, Del Prete Z,
Rosenthal N, Molinaro M, Protasi F, Fanò G, Sandri M, Musarò A: Skeletal muscle is a primary target of SOD1G93A-mediated toxicity. Cell Metab 2008;8:425-436.

10 Miller TM, Kim SH, Yamanaka K, Hester M, Umapathi P, Arnson H, Rizo L, Mendell JR, Gage FH, Cleveland DW, Kaspar BK: Gene transfer demonstrates that muscle is not a primary target for non-cell-autonomous toxicity in familial amyotrophic lateral sclerosis. Proc Natl Acad Sci USA 2006;103:1954619551.

11 DeFronzo RA, Gunnarsson R, Björkman O, Olsson M, Wahren J: Effects of insulin on peripheral and splanchnic glucose metabolism in noninsulin-dependent (type II) diabetes mellitus. J Clin Invest 1985;76:149-155.

12 Astin KJ, Wilde CE, Davies-Jones AB: Glucose metabolism and insulin response in the plasma and CSF in motor neurone disease. J Neurol Sci 1975;25:205-210.

13 Brown JC, Kater RM: Pancreatic function in patients with amyotrophic lateral sclerosis. Neurology 1969;19:185-189.

14 Cumings JN: Biochemical aspects. Proc R Soc Med 1962;55:1023-1024.

15 Friedman HM, Tzagournis M, Ruppert RD: Pancreatic exocrine and endocrine function in amyotrophic lateral sclerosis. Neurology 1969;19:283.

16 Harno K, Rissanen A, Palo J: Glucose tolerance in amyotrophic lateral sclerosis. Acta Neurol Scand 1984;70:451-455.

17 Moxley RT, Griggs RC, Forbes GB, Goldblatt $\mathrm{D}$, Donohoe K: Influence of muscle wasting on oral glucose tolerance testing. Clin Sci (Lond) 1983;64:601-609.

18 Collis WJ, Engel WK: Glucose metabolism in five neuromuscular disorders. Neurology 1968; 18:915-925.

19 Ionasescu V, Luca N: Studies on carbohydrate metabolism in amyotrophic lateral sclerosis and hereditary proximal spinal muscular atrophy. Acta Neurol Scand 1964;40:47-57.

20 Matthews WB: Discussion on some clinical genetic and biochemical aspects of metabolic disorders of the nervous system. Proc R Soc Med 1958;51:859-863.

-21 Pradat PF, Bruneteau G, Gordon PH, Dupuis L, Bonnefont-Rousselot D, Simon D, Salachas F, Corcia P, Frochot V, Lacorte JM, Jardel C, Coussieu C, Forestier NL, Lacomblez L, Loeffler JP, Meininger V: Impaired glucose tolerance in patients with amyotrophic lateral sclerosis. Amyotroph Lateral Scler 2010;11:166171.

22 Quick DT, Greer M: Pancreatic dysfunction in patients with amyotrophic lateral sclerosis. Neurology 1967;17:112-116.

23 Reyes ET, Perurena OH, Festoff BW, Jorgensen R, Moore WV: Insulin resistance in amyotrophic lateral sclerosis. J Neurol Sci 1984;63:317-324.

24 Saffer D, Morley J, Bill PL: Carbohydrate metabolism in motor neurone disease. J Neurol Neurosurg Psychiatry 1977;40:533-537.

25 Steinke J, Tyler HR: The association of amyotrophic lateral sclerosis (motor neuron disease) and carbohydrate intolerance. A clinical study. Metabolism 1964;13:1376-1381.

26 Desport JC, Preux PM, Magy L, Boirie Y, Vallat JM, Beaufrere B, Couratier P: Factors correlated with hypermetabolism in patients with amyotrophic lateral sclerosis. Am J Clin Nutr 2001;74:328-334.

27 Desport JC, Torny F, Lacoste M, Preux PM, Couratier P: Hypermetabolism in ALS: correlations with clinical and paraclinical parameters. Neurodegener Dis 2005;2:202-207.

28 Gurney ME, Pu H, Chiu AY, Dal Canto MC, Polchow CY, Alexander DD, Caliendo J, Hentati A, Kwon YW, Deng HX, et al: Motor neuron degeneration in mice that express a human $\mathrm{Cu}, \mathrm{Zn}$ superoxide dismutase mutation. Science 1994;264:1772-1775.

29 Yim MB, Kang J-H, Yim H-S, Kwak H-S, Chock PB, Stadtman ER: A gain-of-function of an amyotrophic lateral sclerosis-associated $\mathrm{Cu}, \mathrm{Zn}$-superoxide dismutase mutant: an enhancement of free radical formation due to a decrease in $K_{\mathrm{m}}$ for hydrogen peroxide. Proc Natl Acad Sci USA 1996;93:5709-5714. 
-30 Dupuis L, Oudart H, Rene F, Gonzalez de Aguilar J-L, Loeffler J-P: Evidence for defective energy homeostasis in amyotrophic lateral sclerosis: benefit of a high-energy diet in a transgenic mouse model. Proc Natl Acad Sci USA 2004;101:11159-11164.

- 31 Smittkamp SE, Brown JW, Stanford JA: Timecourse and characterization of orolingual motor deficits in B6SJL-Tg(SOD1-G93A)1Gur/J mice. Neuroscience 2008;151:613-621.

-32 Pun S, Santos AF, Saxena S, Xu L, Caroni P: Selective vulnerability and pruning of phasic motoneuron axons in motoneuron disease alleviated by CNTF. Nat Neurosci 2006;9:408419.

33 Wallace TM, Levy JC, Matthews DR: Use and abuse of HOMA modeling. Diabetes Care 2004;27:1487-1495.

- 34 Gupte AA, Bomhoff GL, Swerdlow RH, Geiger PC: Heat treatment improves glucose tolerance and prevents skeletal muscle insulin resistance in rats fed a high-fat diet. Diabetes 2009;58:567-578.

- 35 Azari MF, Lopes EC, Stubna C, Turner BJ, Zang D, Nicola NA, Kurek JB, Cheema SS: Behavioral and anatomical effects of systemically administered leukemia inhibitory factor in the SOD1 $1^{\mathrm{G} 93 \mathrm{~A} G 1 \mathrm{H}}$ mouse model of familial amyotrophic lateral sclerosis. Brain Res 2003; 982:92-97.

-36 Miana-Mena FJ, Munoz MJ, Yague G, Men$\operatorname{dez}$ M, Moreno M, Ciriza J, Zaragoza P, Osta R: Optimal methods to characterize the G93A mouse model of ALS. Amyotroph Lateral Scler Other Motor Neuron Disord 2005;6:5562.
37 Tankersley CG, Haenggeli C, Rothstein JD: Respiratory impairment in a mouse model of amyotrophic lateral sclerosis. J Appl Physiol 2007;102:926-932.

38 Sharp PS, Dick JRT, Greensmith L: The effect of peripheral nerve injury on disease progression in the SOD1(G93A) mouse model of amyotrophic lateral sclerosis. Neuroscience 2005;130:897-910.

39 Lever TE, Gorsek A, Cox KT, O’Brien KF, Capra NF, Hough MS, Murashov AK: An animal model of oral dysphagia in amyotrophic lateral sclerosis. Dysphagia 2009;24:180-195.

40 Smittkamp SE, Spalding HN, Brown JW, Gupte AA, Chen J, Nishimune H, Geiger PC, Stanford JA: Measures of bulbar and spinal motor function, muscle innervation, and $\mathrm{mi}$ tochondrial function in ALS rats. Behav Brain Res 2010;211:48-57.

41 Muller FL, Song W, Jang YC, Liu Y, Sabia M, Richardson A, Van Remmen H: Denervationinduced skeletal muscle atrophy is associated with increased mitochondrial ROS production. Am J Physiol Regul Integr Comp Physiol 2007;293:R1159-R1168.

42 White MF: IRS proteins and the common path to diabetes. Am J Physiol Endocrinol Metab 2005;283:E413-E422.

43 Bloch-Damti A, Bashan N: Proposed mechanisms for the induction of insulin resistance by oxidative stress. Antioxid Redox Signal 2005;7:1553-1567.

44 Holmes BF, Lang DB, Birnbaum MJ, Mu J, Dohm GL: AMP kinase is not required for the GLUT4 response to exercise and denervation in skeletal muscle. Am J Physiol Endocrinol Metab 2004;287:E739-E743.

-45 Lauritzen HP, Ploug T, Ai H, Donsmark M, Prats C, Galbo H: Denervation and high-fat diet reduce insulin signaling in T-tubules in skeletal muscle of living mice. Diabetes 2008; 57:13-23.
46 Leclerc N, Ribera F, Zoll J, Warter JM, Poindron P, Lampert E, Borg J: Selective changes in mitochondria respiratory properties in oxidative or glycolytic muscle fibers isolated from G93AhumanSOD1 transgenic mice. Neuromuscul Disord 2001;11:722-727.

47 Mahoney DJ, Kaczor JJ, Bourgeois J, Yasuda N, Tarnopolsky MA: Oxidative stress and antioxidant enzyme upregulation in SOD1G93A mouse skeletal muscle. Muscle Nerve 2006;33:809-816.

48 Halter B, Gonzalez de Aguilar JL, Rene F, Petri S, Fricker B, Echaniz-Laguna A, Dupuis L, Larmet Y, Loeffler JP: Oxidative stress in skeletal muscle stimulates early expression of Rad in a mouse model of amyotrophic lateral sclerosis. Free Radic Biol Med 2010;48:915-923.

49 Moyers JS, Bilan PJ, Reynet C, Kahn CR: Overexpression of Rad inhibits glucose uptake in cultured muscle and fat cells. J Biol Chem 1996;271:23111-23116.

50 Audet J-N, Gowing G, Julien J-P: Wild-type human SOD1 overexpression does not accelerate motor neuron disease in mice expressing murine SOD1-G86R. Neurobiol Dis 2010; 40:245-250.

51 Turner BJ, Talbot K: Transgenics, toxicity and therapeutics in rodent models of mutant SOD1-mediated familial ALS. Prog Neurobiol 2008;85:94-134.

52 Arisato T, Okubo R, Arata H, Abe K, Fukada K, Sakoda S, Shimizu A, Qin XH, Izumo S, Osame M, Nakagawa M: Clinical and pathological studies of familial amyotrophic lateral sclerosis (FALS) with SOD1 H46R mutation in large Japanese families. Acta Neuropathol 2003;106:561-568. 